\title{
OPTIMALISASI CITRA DALAM PENGHITUNGAN CALSIUM SCORING DENGAN VARIASI SCAN TYPE DAN SLICE THICKNESS \\ (Studi Pendahuluan Dilakukan Dengan Menggunakan Modifikasi Phantom Thorax di RS Telogorejo Semarang)
}

\section{IMAGE OPTIMIZATION IN CALCULATION OF CALCIUM SCORING WITH VARIATION SCAN TYPE AND SLICE THICKNESS}

(Pre Experiment Using Modification Guide Modification Phantom Thorax in Hospital Telogorejo Semarang)

\author{
Bagus Dwi Handoko ${ }^{1}$, Ari Suwondo ${ }^{2}$, Jeffri Ardiyanto ${ }^{3}$ \\ 1,3) Health Polytechnics of Semarang-Indonesia \\ ${ }^{2}$ Diponegoro University, Semarang \\ E-mail: baguz_dh@yahoo.co.id
}

\begin{abstract}
Background : Examination of Calcium scoring in Radiology Departement Telogorejo Hospital Semarang using CINE scan type and recon phase images using a slice thickness of $2.5 \mathrm{~mm}$, this affect will be plaque with small size cann't to calculate. Aim : The Purpose of this study was to determine the variation of parameters of calcium scoring MSCT scan examination right in calculating optimal plaque.

Methods : The study was preceded by Pre experiments using a thorax phantom with an added 3-calcium artificial heart is likened to the RCA, LCX, LAD and have determined the weight and volume. Experiments with 10 patient samples by applying the best parameters from the pre experiment. Statistical analysis of the results of research conducted by Paired T-Test, while the assessment of the quality radiographs evaluated by an expert in this specialist radiology by providing anatomical criteria scores with 3 choices of items (not clear $=1$, is quite clear $=2$ and obvious $=3$ )

Result : The volume of plaque is embedded in the thorax Panthom 900mm3. Results of pre experiments with hellical scan type and pitch of $0.5,0.9,1.3$ in a score of plaque volume is $104 \mathrm{~mm} 3,67 \mathrm{~mm} 3,60 \mathrm{~mm} 3$. While the scan type CINE with slice thickness $0.625 \mathrm{~mm}, 1.25 \mathrm{~mm}$, $2.5 \mathrm{~mm}$ produces a score of volume plaque is $880 \mathrm{~mm} 3,878 \mathrm{~mm} 3,867 \mathrm{~mm} 3$. Further experiments were performed by applying parameters with the best result is CINE scan with variations slice thickness $0,625 \mathrm{~mm}, 1.25 \mathrm{~mm}, 2.5 \mathrm{~mm}$. To determine the best parameters assessment of image quality with the results on slice thickness $0.625 \mathrm{~mm}$ was 2.2 (quite obvious), slice thickness $1,25 \mathrm{~mm}$ scoring average of 2.7 (quite obvious), and slice thickness $2.5 \mathrm{~mm}$ average scoring 2.9 (obviously). While image noise on the slice thickness $0.625 \mathrm{~mm}, 1.25 \mathrm{~mm}, 2.5 \mathrm{~mm}$, namely 2.7(very high), 1.6 (low), 1.1 (low).

Conclusions : Selected parameters that calculate optimal scoring calcium and low noise image for MSCT scan calcium scoring in Telogorejo Hospital Semarang is Scan type CINE with slice thickness variation $1,25 \mathrm{~mm}$
\end{abstract}

Keyword : MSCT Scan Calsium scoring, Scan type, Slice thickness

\section{PENDAHULUAN}

Pemeriksaan MSCT Scan jantung semakin banyak dilakukan dan telah dijadikan sebagai salah satu pilihan pemeriksaan rutin jantung. Agatston (1990) membuat skoring deposit kalsium pada dinding koroner. Skor ini berdasarkan area $\geq 1 \mathrm{~mm} 2$ dan densitas $>130$ HU untuk mengidentifikasi lesi yang terkalsifikasi.

Skor Agatston dihitung secara komputerisasi (perkalian antara volume area dari setiap lesi yang terkalsifikasi dengan densitas tertinggi dari plak/deposit kalsiumnya), disebut sebagai 'calcified plaque burden'. Masing-masing LM, LAD, LCX, RCA dan cabang-cabangnya dibuat skor kalsium, lalu ditotal skornya. Kemudian, dilihat pada tabel /grafik kurva untuk menentukan persentasi kalsium.

Pesawat MSCT Scan di Instalasi Radiologi RS Telogorejo Semarang mempunyai banyak pilihan variasi parameter yang dapat dilakukan yaitu pada Scan type terdapat Scan type secara Hellical dan CINE. Pemeriksaan Calsium scoring di Instalasi Radiologi RS Telogorejo Semarang menggunakan Scan type CINE dan pada fase recon gambar menggunakan slice thickness $2,5 \mathrm{~mm}$.

Penggunaan slice thickness $2,5 \mathrm{~mm}$ pada rekonstruksi gambar tersebut maka dapat dimungkinkan plaque yang berukuran kecil atau mempunyai volume $\leq 2,5 \mathrm{~mm}$ tidak dapat tervisualisasikan sehingga akan mengurangi keakuratan dalam penghitungan calsium score. Sementara pesawat MSCT Scan di RS Telogorejo Semarang memungkinkan untuk dilakukan peningkatan akurasi terhadap hasil penghitungan calsium scoring tanpa ada penambahan dosis radiasi yang diterima oleh pasien.

Tujuan umum penelitian ini untuk mengetahui perbedaan hasil penghitungan nilai calsium scoring dengan pemilihan parameter scan type CINE dengan Hellical. Sedangkan tujuan hhusus nya untuk mengetahui perbedaan hasil nilai calsium scoring dengan menggunakan slice thickness yang berbeda, untuk mengetahui variasi parameter 
yang tepat dalam memberikan hasil penghitungan calsium scoring yang optimal dengan dosis radiasi yang rendah.

\section{METODE}

Jenis penelitian adalah kuantitatif dengan rancangan penelitian pra-eksperimental dengan Jenis one-shot case study yang dimaksudkan untuk menunjukkan kekuatan pengukuran sekelompok subjek dikenai perlakuan tertentu (sebagai variable bebas) kemudian dilakukan pengukuran terhadap variable bebas.

Penelitian didahului dengan studi pendahuluan yang bertujuan untuk mendapatkan pilihan parameter yang mampu menghasilkan penghitungan calsium score yang optimal yaitu dengan menggunakan modifikasi phantom thorax, yaitu phantom thorax diberi tambahan 3 calsium yang diletakan pada phantom jantung. Calsium yang diberikan dengan ukuran yang berbeda diumpamakan sebagai pembuluh darah jantung RCA, LCX dan LAD. Calsium buatan yang diletakan pada phantom sebelumnya telah ditentukan berat dan volume nya sebanyak $900 \mathrm{~mm} 3$.

Hasil dari Studi pendahuluan didapatkan 2 parameter yang mendekati dengan nilai calsium scoring yang dipasangkan pada phantom buatan, kemudian dibandingkan dengan parameter standart yang dilakukan di RS Telogorejo Semarang. Penelitian ini dilakukan di instalasi Radiologi RS Telogorejo Semarang pada bulan April - Juni 2014. Jumlah sampel dalam penelitian ini adalah 10 pasien MSCT Scan Calsium Scoring. Masing-masing dilakukan 3 variasi parameter sehingga dihasilkan 30 variasi parameter dan hasil penghitungan calsium scoring.

Pengolahan data dan analisis data menggunakan komputer yang dilengkapi program SPSS versi 16 for windows. Analisis terdiri dari analisis karakteristik subyek penelitian, analisis univariat, analisis bivariat dan skoring kualitas gambar. Analisa menggunakan uji paired t-test untuk membedakan hasil penghitungan antara parameter stanart di di RS Telogorejo Semarang dengan parameter yang didapatkan dari hasil pre eksperimen.

Penilaian kualitas gambar dilakukan dengan skoring melalui survey questioner terhadap hasil citra imejing dengan melibatkan seorang expert dalam hal ini dokter spesialis radiologi yang sudah berpengalaman dalam pembacaan citra MSCT scan calsium scoring. Kriteria anatomis dalam standard MSCT Scan Calsium scoring irisan axial diberikan skor dengan 3 pilihan item (tidak jelas $=1$, cukup jelas $=2$ dan jelas $=3$ ).

Penelitian ini telah memenuhi persyaratan etik dan telah disetujui untuk dilaksanakan penelitian dengan memperhatikan prinsip - prinsip yang dinyatakan dalam Pedoman Nasional Etik Penelitian Kesehatan (KNEPK) Departemen Kesehatan RI 2007 sesuai dengan surat keterangan Kelaikan Etik Komisi Etik Penelitian Kesehatan Fakultas Kesehatan Masyarakat Universitas Diponegoro.

\section{HASIL}

Hasil dari pre eksperimen pada tabel 1 didapatkan parameter yang optimal dalam menghitung volume calsium scoring pada panthom thorax yaitu pada Scan type CINE variasi slice thickness $0,625 \mathrm{~mm}$ dengan volume yang diperoleh $880 \mathrm{~mm} 3$, Scan type CINE variasi slice thickness $1,25 \mathrm{~mm}$ dengan volume calsium scoring yang diperoleh 878 mm3. sedangkan parameter rutin yang dilakukan di RS Telogorejo yaitu dengan Scan type CINE, slice thickness $2,5 \mathrm{~mm}$, volume calsium scoring yang diperoleh $867 \mathrm{~mm} 3$.

Hasil pre eksperimen pemeriksaan MSCT Scan Calsium Scoring terbaik dalam menghitung volume plaque terdapat pada 1 scan type dan Axial Thickness yang sama, yaitu pada scan type CINE dengan Axial Thickness 2,5. Hasil pre eksperimen diaplikasikan pada eksperimen dengan 10 pasien dimana pada setiap sampel dilakukan 3 variasi parameter yang berbeda sehingga didapatkan 30 hasil. Hasil penelitian pada eksperimen secara statistik menunjukan bahwa hasil penghitungan calsium scoring dengan variasi slice thickness $0,625 \mathrm{~mm}, 1,25 \mathrm{~mm}, 2,5 \mathrm{~mm}$ terjadi perbedaan yang signifikan $(\mathrm{p}<0,05)$.

Tabel 1. Hasil penghitungan calsium scoring pada pre eksperimen dengan variasi parameter-parameter pada pemeriksaan MSCT scan calsium scoring

\begin{tabular}{|c|c|c|c|c|c|c|c|c|c|c|c|}
\hline \multirow{2}{*}{ No } & \multirow{2}{*}{$\begin{array}{l}\text { Scan } \\
\text { type }\end{array}$} & \multirow{2}{*}{ Pitch } & \multirow{2}{*}{$\begin{array}{l}\text { Axial } \\
\text { thick }\end{array}$} & \multirow{2}{*}{$\begin{array}{l}\text { recon } \\
\text { thick. } \\
(\mathrm{mm})\end{array}$} & \multicolumn{3}{|c|}{ Mass (mg) } & \multicolumn{3}{|c|}{ Volume $\left(\mathrm{mm}^{3}\right)$} & \multirow{2}{*}{$\begin{array}{c}\text { Rata- } \\
\text { Rata } \\
\text { Vol. }\end{array}$} \\
\hline & & & & & RCA & LCX & LAD & RCA & LCX & LAD & \\
\hline 1 & Hellical & 0,531 & & 0,625 & 13 & 18 & 11 & 24 & 32 & 24 & 27 \\
\hline 2 & Hellical & 0,531 & & 1,25 & 26 & 35 & 21 & 46 & 65 & 45 & 52 \\
\hline 3 & Hellical & 0,531 & & 2,5 & 52 & 72 & 41 & 94 & 131 & 88 & 104 \\
\hline 4 & Hellical & 0,9 & & 0,625 & 8 & 10 & 10 & 16 & 17 & 20 & 18 \\
\hline 5 & Hellical & 0,9 & & 1,25 & 16 & 18 & 21 & 31 & 33 & 39 & 34 \\
\hline 6 & Hellical & 0,9 & & 2,5 & 32 & 37 & 32 & 62 & 66 & 72 & 67 \\
\hline 7 & Hellical & 1,3 & & 0,625 & 7 & 9 & 8 & 12 & 16 & 16 & 15 \\
\hline 8 & Hellical & 1,3 & & 1,25 & 13 & 17 & 16 & 25 & 31 & 31 & 29 \\
\hline 9 & Hellical & 1,3 & & 2,5 & 28 & 34 & 36 & 51 & 63 & 65 & 60 \\
\hline 10 & CINE & & 0,625 & 0,625 & 507 & 489 & 481 & 871 & 862 & 859 & 864 \\
\hline 11 & CINE & & 0,625 & 1,25 & 508 & 485 & 479 & 874 & 865 & 859 & 866 \\
\hline 12 & CINE & & 0,625 & 2,5 & 499 & 460 & 472 & 862 & 853 & 844 & 853 \\
\hline 13 & CINE & & 1,25 & 0,625 & 508 & 488 & 479 & 871 & 867 & 860 & 866 \\
\hline 14 & CINE & & 1,25 & 1,25 & 507 & 485 & 477 & 868 & 869 & 862 & 866 \\
\hline 15 & CINE & & 1,25 & 2,5 & 502 & 460 & 472 & 866 & 855 & 851 & 857 \\
\hline 16 & CINE & & 2,5 & 0,625 & 503 & 489 & 484 & 871 & 900 & 870 & 880 \\
\hline 17 & CINE & & 2,5 & 1,25 & 501 & 486 & 483 & 867 & 900 & 867 & 878 \\
\hline 18 & CINE & & 2,5 & 2,5 & 497 & 470 & 472 & 864 & 879 & 857 & 867 \\
\hline
\end{tabular}

*no.18 adalah parameter standart yang dilakukan di RS Telogoerjo Semarang

Tabel 2. Hasil analisis uji Paired T-Test pada hasil AJ130

\begin{tabular}{ccccc}
\hline & Kelompok & Mean & SD & Sig. \\
\hline Pair 1 & AJ130 - ST 0,625mm - & 42.500 & 43.252 & 0.013 \\
& AJ130 - ST 1,25mm & & & \\
Pair 2 & AJ130 - ST 0,625mm - & 5.1682 & 566.776 & 0.018 \\
& AJ130 - ST 2,5mm & & & \\
Pair 3 & AJ 130 - ST 1,25mm - \\
AJ130 - ST 2,5mm & 4.7500 & 532.701 & 0.020 \\
\hline
\end{tabular}


Tabel 3. Hasil analisis uji Paired T-Test hasil Mass Calsium scoring

\begin{tabular}{ccccc}
\hline Kelompok & Mean & SD & Sig. \\
\hline Pair 1 & $\begin{array}{c}\text { Mass - ST 0,625mm - } \\
\text { Mass - ST 1,25mm }\end{array}$ & 4.200 & 59.61251 & 0.018 \\
Pair 2 & Mass - ST 0,625mm - & 17.300 & 19.494 & 0.065 \\
& Mass - ST 2,5mm & & & \\
Pair 3 & Mass - ST 1,25mm - \\
& Mass - ST 2,5mm & 13.100 & 18.758 & 0.018 \\
\hline
\end{tabular}

Tabel 4. Hasil analisis uji Paired T-Test hasil Volume Calsium scoring

\begin{tabular}{clccc}
\hline & Kelompok & Mean & SD & Sig. \\
\hline Pair 1 & Voll - ST0,625mm - & 7.600 & 10.167 & 0.042 \\
& Voll - ST 1,25mm & & & \\
Pair 2 & Voll - ST 0,625mm - & 2.08059E2 & 202.37783 & 0.010 \\
& Voll - ST 2,5mm & & & \\
Pair 3 & Voll - ST 1,25mm - & 1.63659E2 & 173.41827 & 0.015 \\
& Voll - ST 2,5mm & & & \\
\hline
\end{tabular}

Tabel 5. Hasil skoring kualitas gambar dengan variasi slice thickness

\begin{tabular}{lccc}
\hline & \multicolumn{3}{c}{ Rata-Rata Skor } \\
\cline { 2 - 4 } \multicolumn{1}{c}{ Kriteria } & $\begin{array}{c}\text { ST. } \\
0,625 \\
\mathrm{~mm}\end{array}$ & $\begin{array}{c}\text { ST. } \\
\text { mm }\end{array}$ & $\begin{array}{c}\text { ST. 2,5 } \\
\mathrm{mm}\end{array}$ \\
\hline $\begin{array}{l}\text { Kejelasan menampakan } \\
\text { plaque pada LM } \\
\begin{array}{l}\text { Kejelasan menampakan } \\
\text { plaque pada LAD }\end{array}\end{array}$ & 1.0 & 2.0 & 3.0 \\
$\begin{array}{l}\text { Kejelasan menampakan } \\
\text { plaque pada LCX }\end{array}$ & 2.3 & 2.7 & 3.0 \\
$\begin{array}{l}\text { Kejelasan menampakan } \\
\text { plaque pada RCA }\end{array}$ & 2.3 & 3.0 & 2.8 \\
\begin{tabular}{l} 
Image Noise \\
\hline
\end{tabular} & 1.9 & 2.7 & 2.7 \\
\hline
\end{tabular}

Analisis Bivariat dalam menguji perbedaan hasil penghitungan calsium scoring yang meliputi Scoring calsium (AJ130), Mass dan volume antara slice thickness $0,625 \mathrm{~mm}$, $1,25 \mathrm{~mm}$ dan $2,5 \mathrm{~mm}$ dilakukan dengan menggunakan uji paired t-test, hasil dapat dilihat pada tabel 2 .

Pada scoring calsium AJ-130 menunjukan bahwa hasil skoring AJ130 antara slice thickness $0,625 \mathrm{~mm}$ dengan slice thickness $1,25 \mathrm{~mm}$ dan slice thickness $2,5 \mathrm{~mm}$ diperoleh nilai signifikansi $0.013(\mathrm{p}<0,05)$ artinya ada perbedaan yang signifikan dengan nilai $\mathrm{p}<0,05$.

Analisis bivariat pada scoring calsium Mass antara slice thickness $0,625 \mathrm{~mm}$ dengan slice thickness $1,25 \mathrm{~mm}$ diperoleh nilai signifikansi $0.018(\mathrm{p}<0,05)$ artinya terdapat perbedaan yang signifikan dengan nilai $\mathrm{p}<0,05$. Pada slice thickness $0,625 \mathrm{~mm}$ dengan slice thickness $2,5 \mathrm{~mm}$ diperoleh nilai signifikansi $0.065(\mathrm{p}>0,05)$ artinya tidak ada perbedaan yang signifikan dengan nilai $\mathrm{p}>0,05$ pada hasil mass calsium scoring. Pada Slice thickness $1,25 \mathrm{~mm}$ dengan slice thickness $2,5 \mathrm{~mm}$ diperoleh nilai signifikansi $0.018(\mathrm{p}<0,05)$ artinya ada perbedaan yang signifikan dengan nilai $\mathrm{p}<0,05$ pada hasil Mass calsium scoring. Hasil dapat dilihat pada tabel 3.

Analisis bivariat pada volume calsium scoring menunjukan bahwa hasil skoring volume antara slice thickness $0,625 \mathrm{~mm}$ dengan slice thickness $1,25 \mathrm{~mm}$ diperoleh nilai signifikansi $0.042(\mathrm{p}<0,05)$ artinya ada perbedaan yang signifikan dengan nilai $\mathrm{p}<0,05$. Pada slice thickness $0,625 \mathrm{~mm}$ dengan slice thickness $2,5 \mathrm{~mm}$ diperoleh nilai signifikansi $0.010(\mathrm{p}<0,05)$ artinya ada perbedaan yang signifikan dengan nilai $\mathrm{p}<0,05$ pada hasil volume calsium scoring. Pada Slice thickness $1,25 \mathrm{~mm}$ dengan slice thickness $2,5 \mathrm{~mm}$ diperoleh nilai signifikansi $0.015(\mathrm{p}<0,05)$ artinya ada perbedaan yang signifikan dengan nilai $\mathrm{p}<0,05$. Hasil dapat dilihat pada tabel 4 .

Pada penelitian ini dilakukan penilaian kualitas gambar masing-masing variasi slice thickness dalam melihat plaque pada pembuluh darah jantung. Hasil skoring kualitas gambar pada penelitian ini dapat dilihat pada tabel 5. Rata-rata skor kualitas gambar dapat dilihat bahwa pada slice thickness $2,5 \mathrm{~mm}$ rata-rata scoring dalam menampakan plaque yaitu 2,8 yang berarti kualitas gambar dalam melihat plaque pada pembuluh darah jantung dengan menggunakan slice thickness $2,5 \mathrm{~mm}$ yaitu baik. Image noise pada slice thickness $2,5 \mathrm{~mm}$ berdasarkan hasil skoring mempunyai skor yang rendah yaitu 1,1. Akan tetapi pada hasil pre eksperimen dengan menggunakan slice thickness 2,5mm menghasilkan selisih skoring yang tinggi (-33 volume calium scoring buatan) sehingga akan mempengaruhi dalam pengelompokan kategori pasien jantung.

Kualitas gambar pada slice thickness $0.625 \mathrm{~mm}$ rata-rata skoringnya adalah 2,2 yang berarti kualitas gambar dalam melihat plaque pada pembuluh darah jantung mempunyai nilai cukup jelas. Kualitas citra dari radiografi salah satunya dipengaruhi adanya noise. Pada studi pendahuluan dengan slice thickness $0.625 \mathrm{~mm}$ hasil penghitungan Calsium scoring menunjukan hasil Volumeplaque yang sesuai dengan plaque pada coronary artery buatan, akan tetapi penilaian yang dilakukan oleh dokter spesialis radiologi menunjukan image noise yang dihasilkan pada slice thickness $0,625 \mathrm{~mm}$ yaitu 2,7 yang berarti image noise yang terjadi sangat tinggi. Image noise yang tinggi akan menyebabkan kontras resolusi menurun, sehingga dapat memungkinkan mengganggu dalam melakukan penghitungan Calsium scoring.

Pada slice thickness $1,25 \mathrm{~mm}$ memiliki rata-rata skoring 2,7 yang berarti pada slice thickness 1,25 mm gambaran pemeriksaan Calsium scoring dalam menampakan plaque pada coronary artery lebih dari cukup jelas, Sedangkan pengukuran secara subjektif Image noise yang terjadi pada slice thicknees $1,25 \mathrm{~mm}$ yaitu : 1,6. Yang berarti image noise yang dihasilkan pada gambaran hasil slice thickness $1,25 \mathrm{~mm}$ masih berada dibawah cukup atau gambaran noise rendah.

Berdasarkan pada penelitian ini semua variasi slice thickness bisa digunakan dalam melihat plaque pada pembuluh darah jantung dengan cukup jelas. Akan tetapi menurut peneliti slice thickness yang tepat untuk dipakai pada pemeriksaan MSCT Scan Calsium scoring yaitu dengan menggunakan slice thickness 1,25mm. Dengan menggunakan slice thickness $1,25 \mathrm{~mm}$ kualitas gambaran yang dihasilkan sudah lebih dari cukup dengan rata-rata skor 2,7 (Jelas) dan Image noise pada gambaran relatif lebih rendah dengan skor rata-rata 1,6 (Rendah). 
Di Rumah Sakit Telogorejo Semarang dalam melakukan pemeriksaan MSCT Scan Calsium Scoring menggunakan parameter slice thickness $2,5 \mathrm{~mm}$. Studi pendahuluan yang dilakukan pada penelitian ini menunjukan selisih Volume dari penghitungan Calsium Scoring sebesar $13 \mathrm{~mm}^{3}$ terhadap slice thickness $0,625 \mathrm{~mm}$ dan $11 \mathrm{~mm}^{3}$ terhadap slice thickness $1,25 \mathrm{~mm}$. Penelitian yang dilakukan oleh Noortje van der Bijl,2010 yaitu dengan membandingkan pemeriksaan MSCT Scan Calsium Scoring dengan slice thickness 0,5mm dengan slice thickness $3,0 \mathrm{~mm}$ pada 100 pasien, hasil dari penelitian menunjukan bahwa dengan menggunakan slice thickness 3,0mm 100 pasien tidak terdapat plaque pada pembuluh darah jantung, kemudian dengan menggunakan slice thickness $0,5 \mathrm{~mm}$ menunjukan ada 21 dari 100 pasien positif terdapat plaque pada pembuluh darah jantung.

Pada penelitian ini didapatkan Scan type CINE dengan slice thickness $1,25 \mathrm{~mm}$ sebagai protokol pemeriksaan MSCT Scan Calsium scoring. Pada pemilihan parameter tersebut menghasilkan dosis radiasi yang relatif lebih kecil dan informasi volume calsium scoring yang lebih akurat. Hasil penelitian yang diperoleh merupakan penelitian pengembangan terhadap parameter-parameter yang dilakukan dalam pemeriksaan MSCT Scan Calsium scoring khususnya yang berpengaruh terhadap penghitungan nilai Calsium scoring, kualitas gambar dan dosis radiasi. Pengembangan atau inovasi yang diperoleh yaitu perubahan terhadap parameter-parameter dalam pemeriksaan MSCT Scan Calsium scoring di RS Telogorejo Semarang dapat dilakukan untuk peningkatan optimalisasi kualitas dalam hal ini kemampuan dalam mendiagnosa patologi plaque dan akurasi dalam penghitungan Calsium scoring yang lebih optimal tanpa menambah dosis radiasi yang diterima oleh pasien, sehingga kemungkinan terjadinya kesalahan dalam melakukan pengkategorian pasien yang menderita penyakit jantung koroner dapat lebih tepat karena plaque yang berukuran lebih kecil dari $2,5 \mathrm{~mm}^{3}$ dapat dinilai.

\section{SIMPULAN}

Studi pendahuluan yang dilakukan menunjukan bahwa pengaturan Scan typeakan memberikan hasil penghitungan calsium scoring yang berbeda. Parameter yang menghasilkan volume calsium scoring paling optimal yaitu : Scan type CINE, Axial Thickness $2,5 \mathrm{~mm}$, slice thickness $0,625 \mathrm{~mm}$; Scan type CINE, Axial Thickness 2,5mm, slice thickness $1,25 \mathrm{~mm}$ Analisis bivariat menunjukan hasil penghitungan calsium scoring antara slice thickness $0,625 \mathrm{~mm}, 1,25 \mathrm{~mm}$ dan slice thickness 2,5mm (sebagai parameter standart RS Telogorejo Semarang) terdapat perbedaan yang signifikan $(\mathrm{p}<0.05)$.

Parameter yang tepat dalam menghasilkan penghitungan calsium scoring paling optimal yaitu Scan type CINE dengan reconstruksi nilai Slice thickness $1,25 \mathrm{~mm}$, dimana dengan Scan type CINE dosis radiasi yang dihasilkan lebih rendah dibandingkan dengan Scan type Hellical dan gambaran noise pada Slice thickness $1,25 \mathrm{~mm}$ lebih rendah sehingga hasil penghitungan calsium scoring lebih optimal.

\section{DAFTAR PUSTAKA}

A deRoos, Kroft L J M, Bax J J, Lamb H J, and Geleijns J. 2006.Cardiac applications of multislice computed tomography (British Institute of Radiology). tanggal akses 13 Agustus 2013.

Adams, Robert. 2009. Heart Diseases and Stroke Statistics. Jurnal Of The Amerikan Heart Association; 199.

Agatston AS, Janowitz WR, Hildner FJ, Zusmer NR, Viamonte M, Detrano R. 1990. Quantification of coronary artery calsium using ultrafast computed tomography. J. Am Coll Cardiol.

Bontrager, Kenneth L. 2001.Textbook of Positioning and Related Anatomy, Fifth Edition. CV. Mosby Company, St. Louis.

Bushong, Stewart C. 2001. Radiologic Science for Technologists.Physics, Biology and Protection.7th edition. Missouri: The CV Mosby Company.

Bushberg.J.T. 2003.The Essential Physics Of Medical Imaging, Second Edition. Philadelphia. USA.

Ermadji Prajitno M. 2005.'Non Invasive Coronary Angiography' Dengan 'Multiple Slice Ct' (MSCT).Multi sclice CT Medical Seminar, Siloam Gleneagles Hospital Karawaci.

General Electric Company. 2002. SmartScore Coronary Artery Calcification Scoring Operator Manual,. Milwaukee, Wisconsin 53201 U.S.A 2001-2002

Nagel, H.D. 2007.Multislice CT Technology,Germany, Www.multislice.com akses 12 Agustus 2013.

Noortje van der Bijl, Paul W. de Bruin, Jacob Geleijns, Jeroen J. Bax, Joanne D. Schuijf, Albert de Roos , et al. 2009. Assesment of coronary artery calcium by using volumetric 320-row multi detector computed tomography : Comparison of $0.5 \mathrm{~mm}$ with $3.0 \mathrm{~mm}$ slice thickness. akses pada tanggal 12 Agustus 2013

Ohnesorge. B.M., Becker. C.R., Flohr. T.G., Reiser.M.F. 2002.Multi-slice CT in Cardiac Imaging, Springer-Verlag Berlin Heidelberg Germany.

Prokop, M.,dan Galanski, M. 2007. Spiral and Multislice Computed Tomography of The Body, Thieme, Stuttgart New York.

Radiological Society of North America, Inc. (RSNA).2007. Cardiac CT for Calcium Scoring,; Akses 18 Oktober 2012

Seeram, Euclid, RT. 2001. Computed Tomography, Physical Principles, Clinical Applications, and Quality Control, WB. Saunders, Pennsylvania, USA.

SmartScore Coronary Artery Calcification Scoring Operator Manual, General Electric Company. Milwaukee, Wisconsin 53201 U.S.A, 2001-2002

Sylvia A. Price. 2003. Pathophysiology Clinical Concept of disease processes. 6th ed.Mosby: EGC. 